\title{
COVID-19 vaccine exclusion based on legal residence is unwise and unethical
}

\author{
Lisa M. Lee ${ }^{1} \mathbb{D} \cdot$ Abigail E. Lowe $^{2}$ (D) Matthew K. Wynia ${ }^{3}$
}

Accepted: 10 April 2021 / Published online: 3 May 2021

(c) The Author(s), under exclusive licence to Springer Nature Limited 2021

\section{Dear Editor,}

We believe that COVID-19 vaccine exclusion based on legal residence is unwise and unethical.

Some private and public sector officials in the United States (US) have considered excluding otherwise eligible recipients from COVID-19 vaccination based on individuals' legal residence status. Such policies reveal a misunderstanding of how viruses spread and mutate, as well as a lack of clarity about the ethical obligations of governmental public health to communities. It is both prudent and ethically obligatory for leaders at all levels to mitigate virus transmission throughout the population, even when that population is the entire globe [1].

Worrisome news reports of COVID-19 vaccine program exclusions have arisen at every level of the health care system, from hospitals to international initiatives. Some hospitals in the US have administered vaccines to administrative staff at low risk of infection before reaching higher-risk individuals in the local community [2]. In Nebraska, officials followed national guidance and included meatpacking and food-processing workers in phase $1 \mathrm{~B}$ prioritization plans, but then announced that undocumented workers would have lower priority [3]. Meanwhile, some Floridians have called for restricting vaccines to permanent residents, excluding not only undocumented workers but also an estimated 1 million 'snowbirds' (people who live in northern states in summer and Florida in winter) [4]. Globally, some high-income

Lisa M. Lee

LMLee@vt.edu

Abigail E. Lowe

abigail.lowe@unmc.edu

Matthew K. Wynia

matthew.wynia@cuanschutz.edu

1 Scholarly Integrity and Research Compliance and Department of Population Health Sciences,

Virginia Tech, Blacksburg, VA, USA

2 University of Nebraska Medical Center, Omaha, NE, USA

3 University of Colorado Anschutz Medical Campus, Aurora, CO, USA 
countries with more ample supplies of vaccines (in some cases more than needed to vaccinate their entire population) have been reticent to share them with lower income nations, presenting challenges to equitable distribution [5].

Coronavirus transmission does not discriminate by employment level, duration of residence in a jurisdiction, or legal status in a country. It simply requires two or more people to be near enough to each other, with one being infectious. In a given community, choosing to leave some people unprotected by limiting vaccinations based on employment or legal status - or any other factors irrelevant to viral transmission-leaves that community vulnerable to continued viral transmission. Continued viral transmission promotes ongoing development of viral mutations. Viral mutations create more opportunities for strains to arise that are resistant to existing therapeutics and vaccines, creating additional waves of COVID-19 hospitalizations and deaths. These basic facts about viral transmission and mutation dynamics create a strong prudential justification for providing vaccines to all persons present in a community, regardless of legal status, with prioritization based only on risk of infection, risk of spreading infection to others, and risk of serious morbidity or mortality.

For hospitals and health systems in the US, the moral obligation to rapidly reduce viral transmission is rooted in the organization's obligations to its community. Hospitals of different types have differing legal obligations, but under no ethical health system is it acceptable to serve the interests of its administrators over those of the community. For not-for-profit hospitals this social contract may be legally enforceable, but for-profit hospitals also typically have a clear mission statement featuring a social compact that prioritizes patient care and community well-being. As a result, when hospitals or health systems receive shipments of vaccine-especially a vaccine funded by the federal government-ethically, they become community stewards, not owners, of the vaccine.

For governments, the moral obligation to include the entire population in COVID-19 vaccine programs is rooted in the obligation to protect and promote public health and safety of its population. In the US, individual states' legal powers to protect public health are seated in the constitution, administrative law, and other legal authorities. But these legal duties are rooted in several core humanitarian ethical principles of public health, including public beneficence, solidarity, health justice and equity, and reciprocity.

Public beneficence, the duty of a government to act to maximize public benefit and minimize public harm, is the foundational moral commitment that undergirds public health [1]. The ethical principle of solidarity acknowledges interdependence and shared vulnerability within a community, calling on each member to respect every other community member, regardless of individual productivity, abilities, or social standing [6]. Health justice and equity have gained prominence in the ethical landscape of public health, focusing on fair distribution of health burdens and benefits within a population and ensuring that, at minimum, public health activities do not exacerbate underlying health inequities [6]. Finally, the concept of reciprocity requires recognizing relationships of mutual exchange and acknowledging that those who accept disproportionate burdens are owed fair consideration in return [6].

These ethical principles point toward disregarding legal status and all other factors unrelated to infection when allocating scarce COVID-19 vaccines. All persons 
present in a community benefit when allocation strategies rapidly reduce community transmission of the virus. Solidarity directly calls for treating all community members with equal respect. Health justice and equity similarly focus on ensuring that disadvantaged groups are not further disadvantaged by allocation protocols. And reciprocity recognizes that measures to protect the public good during this pandemic have already imposed disproportionate burdens on undocumented workers, who often work in close quarters in essential industries without adequate personal protective equipment. In particular, food-processing workers regardless of immigration status have assumed extra risks; all of these workers, regardless of immigration status, are therefore owed prioritization in vaccine allocation.

Finally, the federal governments of high-income countries are also in a position to make vaccine allocation decisions that lead to more or less rapid reduction in the spread of infection worldwide. Decisions to send vaccines outside the country while some persons within remain unvaccinated are politically challenging. Nations have obligations to their populations that they do not have to people outside their borders but keeping vaccine for use only inside one country would be as counterproductive [7] and unethical as doing so at the level of a hospital or state. Vaccines should be put to use where they are most needed to halt viral transmission. Nations should share vaccine with others as soon as possible, with greater sharing by governments in possession of vaccines as their populations reach acceptable levels of herd immunity. Failure to do so will lead to more viral mutations in addition to those already circulating. Mutations do not stay in one country, as we have seen, which creates a strong prudential reason to send vaccines as quickly as possible to areas in the world where they are most needed.

Vaccination against COVID-19 is the most effective tool we have to curtail this pandemic. The fastest, most economical, and most ethical way to reduce viral transmission is to focus on vaccinating all persons living in any community who are at highest risk of contracting the illness and transmitting it to others. For an organization, a state, or a nation, this means that the fastest and most enduring route to protecting citizens from COVID-19 is to eliminate legal residence or worker status as a condition of vaccine allocation.

Acknowledgements The authors thank members of the University of Nebraska Medical Center Global Center for Health Security Ethics Advisory Committee for numerous thoughtful deliberations on this topic: David Brett-Major, Teck Chuan Voo, Kelly K. Dineen, Alva O. Ferdinand, Nancy E. Kass, Rachel E. Lookadoo, Seema Mohapatra, Nneka Sederstrom, and Sarah Shannon. We would also like to thank Sara Donovan for administrative and project management support of the Ethics Advisory Committee.

Funding No external funding supported this work.

\section{Declarations}

Conflict of interest The authors have no conflicts of interest to report. 


\section{References}

1. Presidential Commission for the Study of Bioethical Issues (PCSBI). Ethics and Ebola: public health planning and response. Washington, DC: PCSBI; 2015.

2. Rosenthal E. Yes, it matters that people are jumping the vaccine line. New York Times, Jan 28, 2021. https://www.nytimes.com/2021/01/28/opinion/covid-vaccine-line.html. Accessed 2 Feb 2021

3. Burbach C. US citizenship not a requirement for COVID vaccine in Nebraska. Associated Press, January 6, 2021. https://omaha.com/news/state-and-regional/us-citizenship-not-a-requirement-forcovid-vaccine-in-nebraska/article_4da1d138-4fac-11eb-89a9-c3052b2306d2.html. Accessed 2 Feb 2021

4. Madan M, Ceballos A. Florida vaccine residency rule may block access for migrant farmworkers. Associated Press, January 22, 2021. https://www.tampabay.com/news/florida-politics/2021/01/22/ florida-vaccine-residency-rule-may-block-access-for-migrant-farmworkers/. Accessed 2 Feb 2021

5. So AD, Woo J. Reserving coronavirus disease 2019 vaccines for global access. BMJ. 2020. https:// doi.org/10.1136/bmj.m4750.

6. American Public Health Association (APHA). Public health code of ethics. Washington, DC: APHA; 2019.

7. Cakmakli C, Demiralp S, Kalemli-Ozcan S, et al. The economic case for global vaccinations: an epidemiological model with international production networks. National Bureau of Economic Research, 2021. https://www.nber.org/papers/w28395. Accessed 2 Feb 2021

Publisher's Note Springer Nature remains neutral with regard to jurisdictional claims in published maps and institutional affiliations.

Lisa M. Lee PhD, MA, MS is Associate Vice President for Research and Innovation and Professor of Population Health Sciences at Virginia Tech, Blacksburg, Virginia, USA.

Abigail E. Lowe MA is Director of Ethics and Public Health Preparedness, at the Center for Preparedness Education, University of Nebraska Medical Center, Omaha, Nebraska, USA.

Matthew K. Wynia MD, MPH is Director of the Center for Bioethics and Humanities and Professor of Medicine and Public Health at University of Colorado Anschutz Medical Campus, Aurora, Colorado, USA. 